\section{Distimia. Do mau humor ao mal do humor: diagnóstico e tratamento}

Moreno RA, Cordás TA, Nardi AE et al. Artmed; 2010. 118 p. ISBN 978-85-363-2165-3.

Apesar de identificada já no século XIX, a distimia é, ainda hoje, pouco identificada pelo médico clínico e até mesmo pelo psiquiatra, em virtude de sua complexidade sintomática e, por vezes, pela confusão entre ser, efetivamente, um quadro clinico passível de diagnóstico e tratamento ou um transtorno de personalidade.

Assim é que, mais que bem-vinda, esta $3^{\text {a }}$ edição de Distimia é absolutamente essencial para todos os profissionais da área da saúde mental, particularmente para os psiquiatras que têm, em sua linha de frente, o paciente difícil, mal-humorado e "azedo", mas que pode ser adequadamente tratado, como muito bem sugere, em sua capa, o limão cortado, que por azedo, pode ser transformado em doce suco.

Os autores principais Ricardo Moreno, Táki Cordás e Egídio Nardi, além de Dóris Moreno, se juntam a uma plêiade de
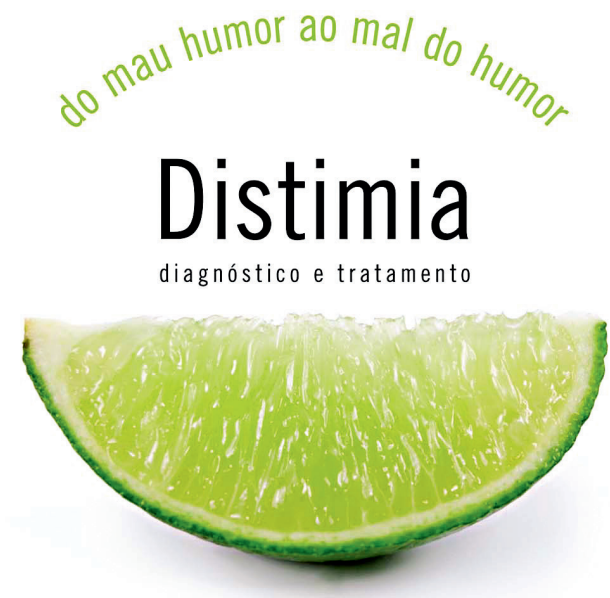

Ricardo Alberto Moreno

Táki Athanássios Cordás

Antonio Egidio Nardi e colaboradores

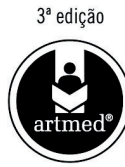

novos colaboradores e constroem uma revisão aumentada e consistentemente importante.

Os novos capítulos sobre Emoção, afetividade e humor e Desfechos físicos, psicológicos e sociais e a divisão da terapêutica em Tratamento farmacológico da distimia e Abordagens psicossociais da distimia ampliam a visão sobre esta doença, com benefícios tanto para o assistente, quanto o paciente, sua família e rede social.

No primeiro capítulo, Distimia - origem e evolução do conceito, Táki Cordás e Eduardo Aratangy discutem a origem e a evolução do conceito de forma pertinente e definitiva, mostrando que o pensamento inicial de Kahlbaum, em 1863, apresenta consistência com o pensamento atual, em que pese o fato de que autores de peso e mesmo as primeiras classificações, ao longo do século XX, associaram distimia à "neurose depressiva", com ênfase sobre a personalidade e não sobre o quadro sintomático. A evolução dos estudos sobre os transtornos do humor e sua atual alocação dentro das classificaçôes atuais permitiu que os autores afirmem: "Cem anos após Kraepelin, aceita-se a distimia como uma variante atenuada no espectro dos transtornos afetivos".

No capítulo 2, Emoçôes, afetividade e humor, Ricardo Moreno e os jovens Rodolfo Campos e Marcio de Souza descrevem e enfatizam a importância da vida afetiva caracterizada pela emoção e sentimentos como uma somatória para o humor, contribuindo ainda mais para uma avaliação objetiva do conceito médico de depressão. Enfatizam o humor normal com seus altos e baixos, identificando o humor patológico como aquele no qual os fatores de risco genéticos e ambientais interagem de forma complexa, desde os primórdios da vida das pessoas, para o surgimento do quadro depressivo.

Dóris Moreno e Ricardo Moreno trazem, no capítulo 3, Diagnóstico e quadro clínico, uma excelente comparação entre as classificaçōes atuais (Classificação Internacional de Doenças-10a edição e Manual Diagnóstico e Estatístico de Transtornos Mentais$4^{a}$ edição-Texto revisado), mostrando prevalência, características demográficas, perfil sintomatológico e curso, desde a infância ("período em que frequentemente tem seu início") até a terceira idade. Consideram, apropriadamente, que a distimia ainda é pouco diagnosticada e mal tratada, o que contribui para sua cronificação e maior prejuízo funcional. Por anteceder episódios depressivos maiores, desenvolvendo as chamadas "depressões duplas", os autores consideram ser uma boa oportunidade para o desenvolvimento de açôes preventivas em psiquiatria. Importante para o diagnóstico é diferenciá-la da depressão maior, não por força dos sintomas, mas pela cronicidade.

No capítulo 4, Desfechos físicos, psicológicos e sociais, Luiz Felipe Costa e Mireia Roso acrescentam a importância do diagnóstico precoce, enfatizando que não se considere a distimia um diagnóstico secundário, principalmente pelas sequelas relacionadas ao início precoce dos sintomas. Alertam para maior risco de suicídio quando em comorbidade com depressão maior, uso de 
substâncias e doenças crônicas físicas. Consideram que boa adesão ao tratamento e conhecimento dos possíveis desfechos deve ser parte do planejamento terapêutico.

Novamente, Ricardo Moreno, Marcio de Souza e Rodolfo Campos trazem, no capítulo 5, Sua relação com outros quadros psiquiátricos, a dificuldade do paciente em aceitar sua condição clinica, por confundi-la com um "modo de ser", alertando para a concomitância com episódio/transtorno depressivo maior, transtornos de ansiedade, as dependências químicas, notadamente o álcool e, não menos importante, os transtornos de personalidade. Pequena citação é feita em relação a outras doenças médicas. Em razão da importância cada vez maior da atenção às comorbidades psiquiátricas com doenças físicas, parece pertinente a sugestão para que, em outra edição, este tema possa ser um capítulo à parte.

Aline Sardinha e Egidio Nardi, em Distimia e personalidade, capítulo 6, apresentam um completo exame sobre estas questões, particularmente sobre transtorno de personalidade depressiva e distimia. Consideram que a utilidade clínica das classificaçôes multiaxiais são adequadas e inegáveis, e discutem estudos que delineiam achados prós e contras estas duas instâncias patológicas. Como a prática clínica limita-se a uma observação transversal do curso e evolução dos transtornos de personalidade e humor, consideram fundamental a avaliação da personalidade diante de pacientes com hipótese de distimia ou depressão. A afirmação “a ideia de que um transtorno de personalidade é imutável nunca foi testada" fica à avaliação dos leitores.

No capítulo 7, Tratamento farmacológico da distimia, Marina Mochcovitch e Egidio Nardi constatam que, por insuficiência de familiarização com o diagnóstico, a distimia é pouco reconhecida e tratada, sendo o sucesso do tratamento ônus da equipe, da família e do paciente. Historiam o uso de diversos psicofármacos desde o início e constatam ser a distimia uma doença crônica e recidivante, mas responsiva à farmacoterapia. Fazem uma adequada revisão de estudos e fármacos já utilizados e em uso, com sugestôes que devem nortear todo o tratamento, com posologia, duração e interaçôes medicamentosas que podem ocorrer pela ação dos fármacos sobre as enzimas do citocromo P450. Alertam que distímicos parecem mais sensíveis aos efeitos adversos dos medicamentos.

No último capítulo Abordagens psicossociais da distimia, Mireia Roso, Luiz Felipe Costa e Ligia Ito destacam a psicoeducação como fator importante na adesão do paciente e familiares aos tratamentos psicoterápicos e farmacológicos. Apresentam os pressupostos básicos de cada uma das abordagens que consideram eficazes e mostram estudos que validam o uso da psicoterapia em conjunto com o arsenal psicofarmacológico, como fator de sucesso no tratamento.

Enfim, é uma obra absolutamente de fôlego, em se tratando de tema tão importante, quanto negligenciado na clinica psiquiátrica. É de fácil e agradável leitura, sem deixar, em instante algum, a característica científica que deve qualificar publicações deste porte.
Colocar este livro ao alcance do residente, do psiquiatra e demais profissionais da saúde mental, pode engendrar discussões positivas, que levem a correções de rumo no sentido de maior exposição do tema em jornadas, seminários e mesmo nos grandes congressos. Com o elogio pela terceira edição, não é demais repetir: não é uma obra apenas necessária, é essencial.

\section{Geraldo Francisco do Amaral}

Departamento de Saúde Mental e Medicina Legal, Faculdade de Medicina, Universidade Federal de Goiás (UFG), Goiânia, GO, Brasil

Programa de Pós-Graduação em Ciências da Saúde, Universidade Federal de Goiás (UFG), Goiânia, GO, Brasil Centro de Referência em Transtornos do Humor, Hospital das Clínicas, Universidade Federal de Goiás (UFG), Goiânia, GO, Brasil 